\title{
Study on the possibility of application of a compact roll over protective structure for agricultural wheeled narrow track tractors
}

\author{
Danilo Monarca, Massimo Cecchini, Andrea Colantoni, Simone Di Giacinto, Giuseppina \\ Menghini, Leonardo Longo \\ Department of Agriculture, Forest, Nature and Energy (DAFNE), University of Tuscia, Italy
}

\begin{abstract}
Since occupational accidents often occur in farm tractor drivers, it is extremely important to focus the attention on specific devices in order to avoid risks from tractor overturning. This phenomenon is actually considered as the leading cause of deaths or injuries related to agricultural work. The system adopted to reduce the above-mentioned risk consists of passive protection devices aimed at preventing the hazardous event which may affect workers' health. More precisely, the tractor chassis (i.e. ROPS) and the proper seat belt define a "safety volume" around the worker. The aim of the present research is to carry out tests on narrow-track wheeled tractors with fixed roll over protective structures in those areas - such as hazel and olive groves and vineyards - where problems related to under-tree activities occur. This is to implement planting layout and/or cultivation techniques which can be considered suitable for tractors with roll over protective structures. According to that, their project parameters - i.e. safety volume, seat position and typology, test methods - can be successfully modified and improved. The results show that nowadays only a few agricultural vehicles are provided with specific fixed devices able to work under tree without damaging orchards.
\end{abstract}

Correspondence: Massimo Cecchini, Department of Agriculture, Forest, Nature and Energy (DAFNE), University of Tuscia, Via S. Camillo de Lellis snc, 01100 Viterbo, Italy.

Tel. +39.0761.357.357 - Fax: +39.0761 .357 .453 .

E-mail: ergolab@unitus.it

Key words: tractor, overturning, roll over protective structure, safety.

Contributions: the authors contributed equally.

Conflict of interests: the authors declare no potential conflict of interests.

Conference presentation: part of this paper was presented at the $10^{\text {th }}$ Italian Conference AIIA (Associazione Italiana di Ingegneria Agraria), 2013 September 8-12, Viterbo, Italy.

(C) Copyright Danilo Monarca et al., 2013

Licensee PAGEPress, Italy

Journal of Agricultural Engineering 2013; XLIV(s2):e136

doi:10.4081/jae.2013.s2.e136

This article is distributed under the terms of the Creative Commons Attribution Noncommercial License (by-nc 3.0) which permits any noncommercial use, distribution, and reproduction in any medium, provided the original author(s) and source are credited.

\section{Introduction}

In Italy the fatal accidents at work in industry and services have marked, according to the INAIL, a significant drop in the past 10 years (Laurendi and Vita, 2011). Unlike other sectors, where the trend of fatalities follows a trail decreasing for several years, the agricultural sector has also recorded increases (INAIL, 2012). The highest number of fatal accidents, resulting in the death or permanent disability envolving the operators of agricultural tractors, demonstrates the inefficiency of the current safety devices mounted on tractors. The system to reduce the consequences of the overturning of agricultural vehicles is made up of passive protection devices, i.e. devices designed to prevent or reduce the severity of the damage caused by the overturning of the machine (Arana et al., 2010). The frame structure ROPS (Roll Over Protective Structure), with a restraint system (seat belt) creates and guarantees, around the operator, "a volume of security" or "free zone" (Kim et al., 2011). Indeed in the case of overturning, the risk for the operator to remain sandwiched between the constituent parts of the tractor and the ground, is reduced if the operator remains within the volume formed by the protective structure. In smaller tractors, operator, during overturning, must bend his upper body forward until it rests against the steering of the tractor in order to stay in the safety volume. In many tractors protection devices are collapsible in order to facilitate the storage and some working phases. The possibility of lowering the ROPS promotes improper use while working under the canopy of trees, because of their contact with the branches of the trees or the support structures for the breeding of specific crops ("tendone" system). Reduction is obtained by simply sliding a locking pivot without the use of a special tool, contrary to a general principle of security that requires that all protective devices can only be removed using special tools; numerous fatal accidents are determined by the tractor overturning, resulting in crushing the operator due to the failure repositioning in security position of that structure. In Italy the adjustment of tractors in use, through the installation of the protective device, is made compulsory for both employers and the self-employed, by Legislative Decree 81/2008. Point 2.4 of Part II of Annex V to the Legislative Decree 81/2008 refers to the need to limit the risks arising from work equipment rollover (overturning), through the integration of appropriate safety devices (cab or frame protection).

The Framework Directive 2003/37/EC of 26 May 2003 concerning the type-approval of wheeled agricultural or forestry tractors, their trailers and interchangeable towed machinery, was enacted with the purpose of define processes, whether of a technical nature, to eliminate barriers in the exchange of goods within the European Community. Directive 2003/37/EC repealed Directive 74/150/EEC and all directives for agricultural or forestry tractor. The inefficiency of the safety device of agricultural vehicles can be attributed to a number of factors: the size of the current systems of protection do not allow to work under the canopy of trees; however one of the major causes of accidents can be attributed to incorrect behaviors of users of agricultural machinery, 
and also to their poor training in the use of appropriate safety devices for machines and equipment. Today, thanks to compulsory training for tractor drivers, they are more conscious of the risks associated with the use of dangerous machinery. The only front on which you can still work to improve the safety of the machines, concerns the safety devices; it is necessary to study the most efficient systems, able to protect the operator at all times (Myers, 2010). The purpose of this work is precisely to: identify the difficulties of the use of safety devices in the event of rollover in working under canopy when it is in full vigor, and to find effective solutions.

\section{Materials and methods}

In this work some farms with the following crops have been selected: hazel, olive, kiwi and vine (the last two grown in tendone system). The choice of these crops is linked to the difficulty of working with tractors under canopy. In the selection of the sample farms the areas with the highest incidence production for individual crops, at the regional level, have been identified.

In Italy the diffusion of crops and methods of cultivation of orchards, are often associated with local traditions of each region. In Latium and Piedmont were analyzed hazel and kiwi plantations, while in Apulia were analyzed vineyards ("tedone" type), and olive groves.

Latium is the region in which are present all the crops under study. The cultivation of hazelnut is concentrated mainly in the province of Viterbo where the growing areas are affected by specific soil and climatic conditions that make the area particularly dedicated to hazelnuts. The planting patterns are the most common ones ( $5 \times 5$ ) m, the territory is mostly hilly. The kiwi cultivation is concentrated almost exclusively in the province of Latina, where the territory is mostly flat.

In Piedmont, the cultivation of the hazelnuts plays a predominant role in the regional economy; the production area par excellence concentrates in Langhe where the topography of the area as strong diversity, alternating plains and hillsides in very steep areas where mechanization is made more difficult. The kiwifruit in this area is not of great importance; however it affects the economy of several local producers. In Piedmont, the actinidia cultivation is usually performed espalier.

The Apulia region is characterized by the presence of olive groves, and in recent years also by younger ones that are best suited to mechanization of the crop as well as its more rational management. Even in these areas is difficult to identify types of farming or planting characteristic patterns considering the great diversity of the farms. In Apulia, the cultivation of the vine is typically "tendone" type and is intended mainly for the production of table grapes of excellent quality. A part of this production is exported. The land is flat and well-suited to mechanization.

For each crop under study was carried out a data acquisition board in which have been reported general indications of the farm and specific indication of the orchard. In addition, for tests carried out in the field with tractors equipped with new rollover protective structures, were prepared technical cards for each machine.

At the stage of identification of the sample farms have followed the acquisition of images in the field and their processing in the laboratory. Sampling was carried out mostly in the period of greatest expansion of the tree crowns, that is, when the situation is worse for the transit of agricultural vehicles in the field. After identifying the firms for which the surveys are carried on the fields were chosen at random, 12 couples of plants in 2 rows ( 6 couples for each row). The lines were chosen in a central position, so as to be representative of the entire plot (Figure 1).

For each couple 3 photos were taken. In the olive groves and hazel groves were chosen couples of plants in a row. For the vine and for kiwifruit, grown with a tendone or pergola system, the six couples of plants were chosen alternately, so as to have a larger surface area and therefore more representative of the entire plot.

The images collected in the field were taken with camera Canon EOS 1000 D with EF-S $15-55 \mathrm{~mm}$. The camera was positioned on a tripod at a distance from the couples equal to planting pattern and a ground height of $1.30 \mathrm{~m}$ (from the center of the lens). To correct the photos by geometric aberration errors and their correct processing it was considered necessary to fix 3 points on each image. The image correction through points spaced according to fixed distance, enables the application of software Autodesk ${ }^{\circledR}$ AutoCAD® Map 3D to obtain images perfectly in line with the plan and overlapping. The 3 points were fixed by the use of a "square" specially designed. The square consists of two aluminum bars $2 \mathrm{~m}$ long, hinged so as to form an angle of 90 degrees; on the tree vertices of the square have been applied targets to highlight the known points. On each couple of plants the square has been positioned on the axis joining the two plants. We took advantage of the use of a spirit level to place the bar of the square in a perfectly horizontal position. In order to detect an image that would highlight the edges of the individual couple of plants has been arranged, behind them, a white piece of cloth. The fabric with a width of $5 \mathrm{~m}$ and a height of $3 \mathrm{~m}$, was set up with two buckles on the side to be hoisted on two telescopic rods (Figure 2).

The photos taken on the site have been elaborated on the computer through the use of software Autodesk® AutoCAD® Map 3D. The pur-

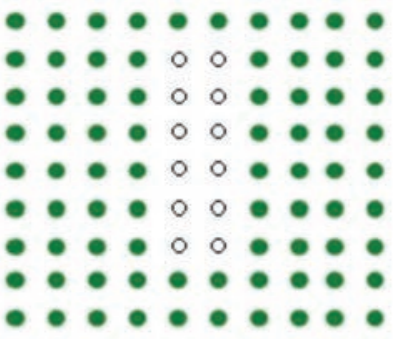

a)

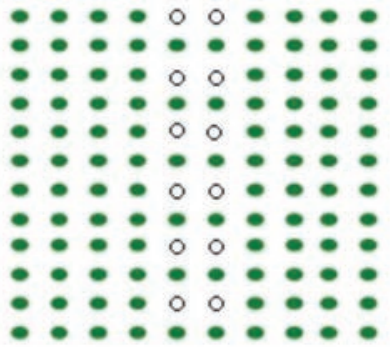

b)
Figure 1. Sampling method: a) olive and hazel groves; b) vineyard and actinidia groves.

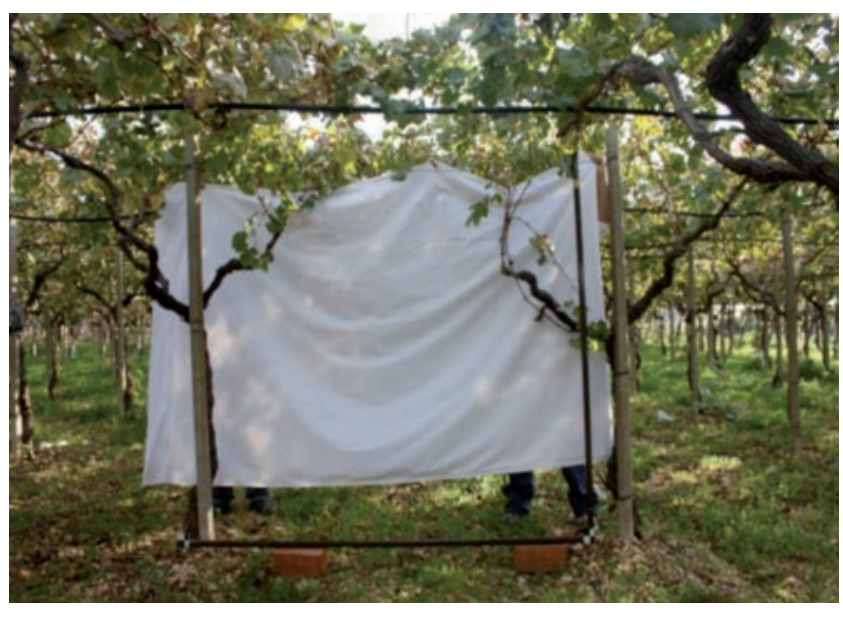

Figure 2. Square and cloth. 
pose is to define, through polyline, the area for the passage of agricultural machines, with particular reference to cultivation of olives, hazels, vines and actinidia.

The computer elaboration is characterized by three phases: in the first the polyline has been drawn on the image of every couple of plants; in the second the characteristic polyline has been obtained; the third phase consists in the overlapping of the edges of tractors (at present more used in orchards) with the characteristic curve of each cultivation.

The following describes the procedure used for the definition of the characteristic curve of a hazelnut cultivation; the procedure is the same for crops of grapes, olives and actinidia, of which the results will be directly proposed. This survey allows us to simulate the passage of agricultural vehicles between the rows of crops. In the first stage of image processing, a polyline for each couple of plants has been realized; in particular this first phase is constituted by the realization of the anchor square on the photo. The anchor square has been realized by means of a polyline whose sides have real dimensions $2 \times 2 \mathrm{~m}$, or the size of the "metal square" in the field. The image put on the work plan has been anchored to the corresponding square with the command: "elastic deformation", which has allowed us to work in scale of proportion, so to keep the size and the actual relations between objects during any stage of computer processing. The anchorage was made by joining the angles of the square, with the three corresponding vertices of the reference square (Figure 3 ).

Once corrected the photo, a polyline has been realized corresponding to the edge of the couple of plants (Figure 4, 5 and 6).

In the second stage the processing of the polyline feature was carried out by the superimposition of polylines made for each couple of plants. For each polyline has been identified the central point of the base that has been made to coincide with the origin of the Cartesian axes (Figure 7) .
Of each polyline have been obtained the coordinates of the vertices (command "list") and processed on an Microsoft ${ }^{\circledR}$ Excel ${ }^{\circledR}$ spreadsheet, obtaining a dispersion diagram. The trend line chosen for the approximation of the characteristic curve is a polynomial of degree $\geq 5$.

In the last phase the trend lines, of every culture studied, have been linked with the lines of the silhouettes of tractors. The contour of the machine is obtained with the same methodology as described in phase 1 for the delimitation of areas beneath the canopy of the trees. The machines used in the simulation of passage in the field and which were obtained by the silhouettes are the following: tractor Same Delfino; tractor Goldoni Star 75; tractor Facma Trifrut; self-propelled harvester Facma C 160 S; self-propelled harvester Facma C 180 S; selfpropelled harvester Facma C 200 S; self-propelled harvester Facma C 300 S; self-propelled harvester Facma C 380 S; self-propelled harvester Facma Semek 1000.

The tests were performed on, vine, actinidia, hazel and olive groves, where has been tested: the possibility of transit of agricultural tractors equipped with new protective structures (six pillars not lowering); the possibility of approaching the tractor to the trunk of the plant; the possibility of transit under the canopy of plants. The new structures, called CROPS (Compact Roll Over Protective Structure), are lower and compact than those of conventional type, adapting better to orchards with wide crown and "tendone" type plants.

For field tests the following tractors equipped with CROPS have been used: New Holland mod. 4040 T, equipped with open CROPS designed and built by INAIL; SAME mod. 35 Frutteto, equipped with open CROPS, designed and built in collaboration with INAIL; Facma mod. Trifrut 85 HP, equipped with CROPS with roof, designed and built by Facma S.r.l. (Vitorchiano, Italy) specifically for the Trifrut.

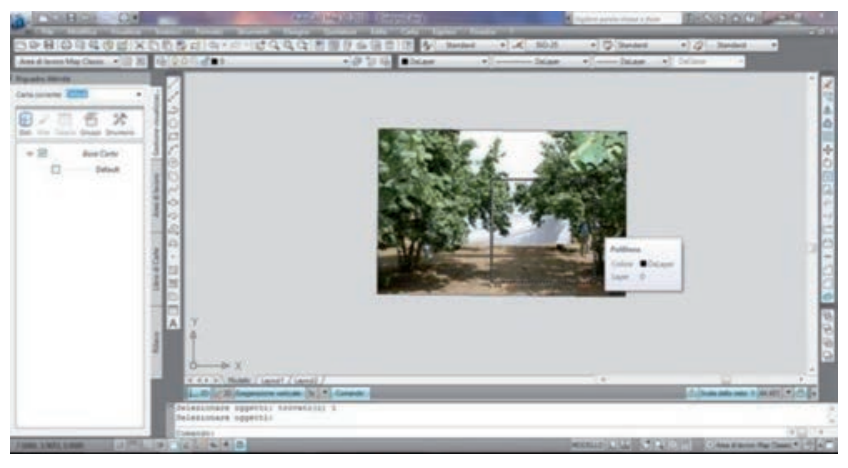

Figure 3. Computer elaboration (step 1).

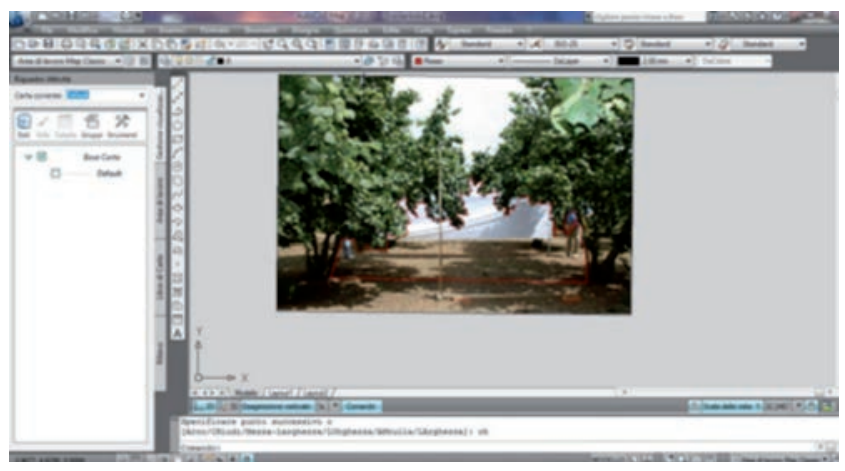

Figure 4. Computer elaboration (step 2).

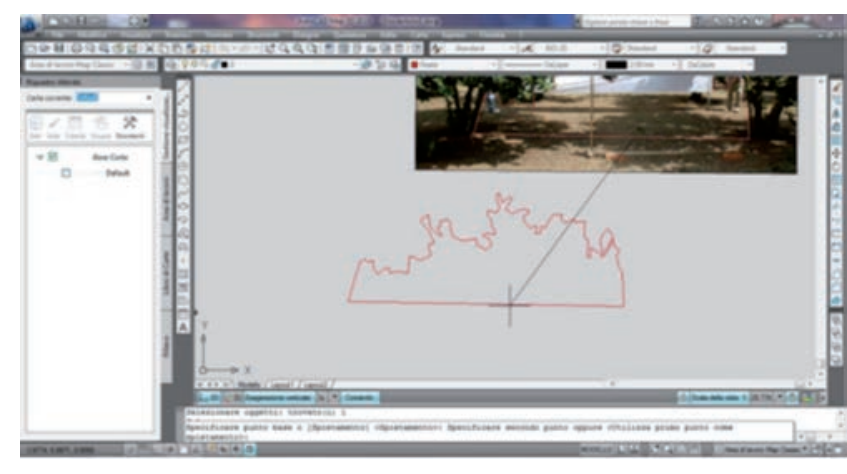

Figure 5. Computer elaboration (step 3).

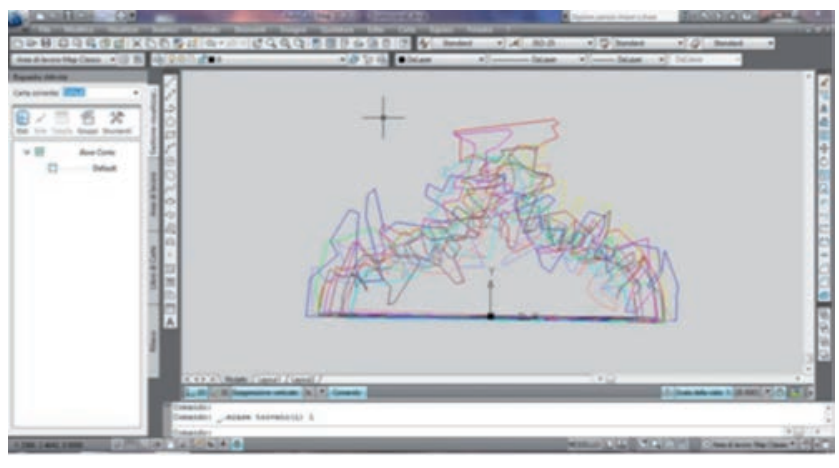

Figure 6. Computer elaboration (step 4). 
The CROPS designed by INAIL comply with the standard ANSI/ASAE S478:1995. The clearance zone defined by this standard, with respect to OECD code 7, is characterized that the height in correspondence of SIP is $50 \mathrm{~mm}$ lower (Gattamelata et al., 2012).

\section{Results}

The characteristic curve of hazelnut has been superimposed on the outlines of some of the most common agricultural vehicles, including the self-propelled harvesters.

In the case of tractors with ROPS raised, the limit is exceeded in height of about $0.5 \mathrm{~m}$, while in the case of the tractor Trifrut, equipped with fixed structure with 6 uprights not folding, exceeding this limit is reduced and is equal to approximately $0.2 \mathrm{~m}$.

Even for the self-propelled harvesting machines the contour exceeds in height the characteristic curve, the height of the machines increases proportionally with the size of the same. Unlike tractors equipped with ROPS, in the self-propelled harvesters, the protection structure has a shape such as to facilitate the sliding of the crown at the time of the passage.

Even the olive tree presents a difficult situation for the passage of tractors with ROPS raised; in particular, the situation more problematic is the Same Delfino (Figure 8), while the Trifrut takes advantage of both the small size and the particular shape of the protective structure which favors the sliding of the branches.

For the kiwifruit canopy grown on a pergola, the difficulty in the passage of agricultural vehicles is accentuated by the presence of fixed

Hazel grove: characteristic curve of the passage section

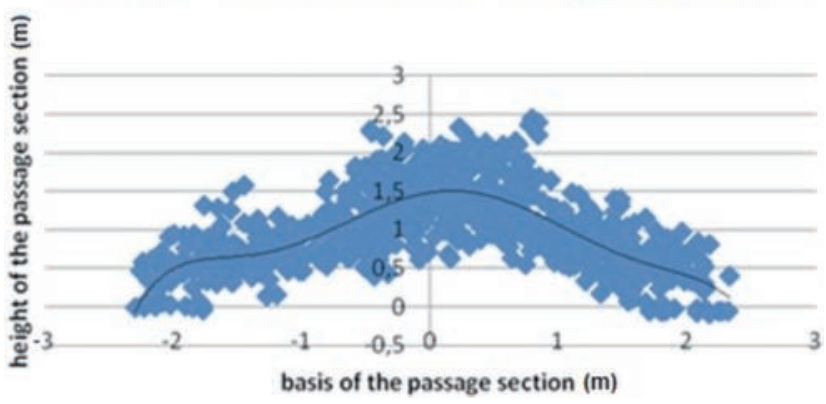

Figure 7. Computer elaboration (step 5).

Olive grove: characteristic curve of the passage section

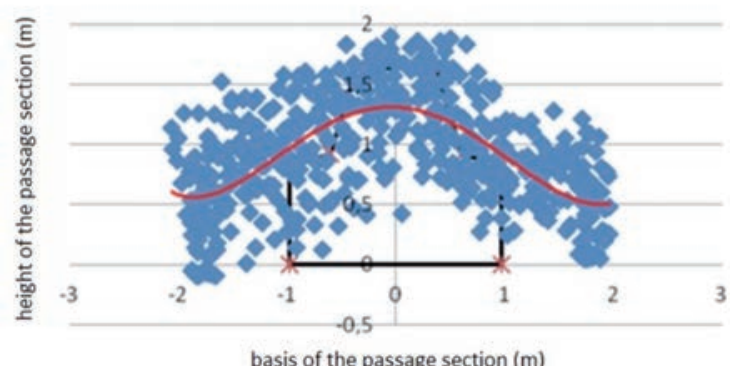

Figure 8. Simulation of transit in olive grove. structures. On the graphs, the maximum height of the fixed structures from the ground is represented by the brown line. In this case the passage of tractors with ROPS raised is absolutely impossible (Figure 9). Only the tractor Trifrut has the conditions to ensure the safe passage of the machine.

As in the case actinidia, also the tendone vine presents a constraint for the transit of agricultural vehicles represented by fixed structures. Even in this case the maximum limit in height, represented by this constraint, is indicated on the graphs by the brown line (Figure 10).

From the simulations it was possible to observe the difficulty of the most common tractors to transit in orchards; to remedy this problem the new structures of protection in the event of rollover have been developed. In this work we investigated the functionality of tractors equipped with CROPS (Compact Roll Over Protection Structure), testing them in field. These structures were mounted on three tractors: New Holland T 4040 F, SAME 35 Delfino Frutteto, Facma Trifrut. The efficiency of the new compact rollover protective structures, with regard to the transitability in orchards, was observed during the work simulation under canopy.

All field tests have produced encouraging results so that one could say that the new protection structures have helped to make it easier and safer to work under canopy. Some tests are visible at the following link: http://youtu.be/gmddrJg3Btg.

\section{Conclusions}

Here is a brief description of the advantages and / or disadvantages

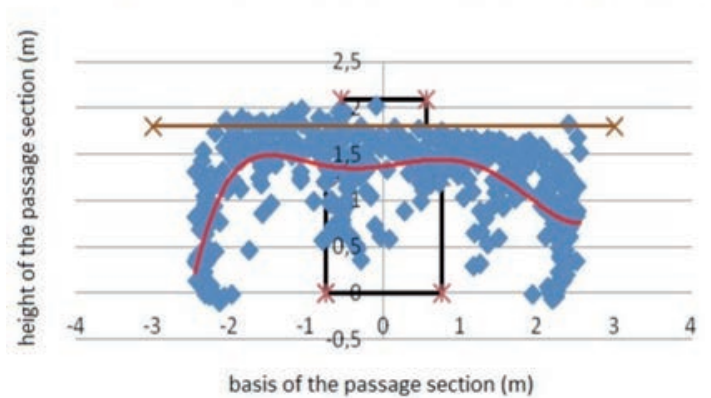

Figure 9. Simulation of transit in kiwifruit grove.

Vineyard: characteristic curve of the passage section

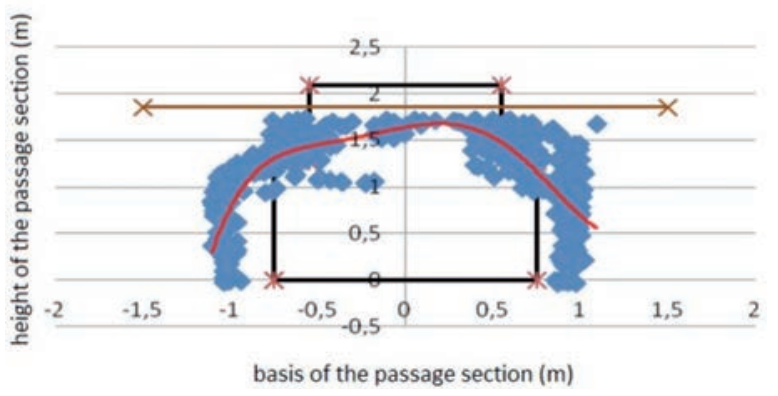

Figure 10. Simulation of transit in vine grove. 
related to each of the three frames installed as rollover protective structures: 1 ) better transitability in the orchard with the presence of dense foliage; the particular conformation of CROPS, especially in the case of the New Holland and Facma, allows a sliding of lower foliage without determining a damage; 2) greater chance of approaching the tractor to the trunk of the plant, the difficulty of working in the vicinity of the foliage often occur in the olive groves; 3) CROPS tractors allow transit below plant canopy for both vineyards and kiwifruit canopy.

It is hoped that these new compact rollover protective structures can have a wide spread. At present there are few agricultural vehicles, equipped with ROPS or other protection systems in the event of rollover, which can perform normal agricultural operations within the orchards, without causing damage to plants.

Two of the tractors tested during the computer simulations, the Same Delfino and Goldoni Star 75, proved to be unfit for transit within an orchard with fixed support structure. From the simulation on computer and from field tests, we observed that the Trifrut works under the canopy of trees and under fixed support structures of some cultivation.

We can say that the field tests can give a measure of the resistance that most branches can oppose to structures of these machines. At the end of the testing phase in the field it will be possible, with the information gathered, to develop new characteristic curves for each cultivation considered, taking into account the actual resistance opposed to the machines by the bigger branches.

\section{References}

Arana, I., Mangado, J., Arnal, P., Arazuri, S., Alfaro, J.R., Jarén, C. Evaluation of risk factors in fatal accidents in agricolture. Spanish Journal of Agricultural Research. 2010. 8: 59.

Gattamelata, D., Laurendi, V., Pirozzi M., Vita, L., Puri, D., Fargnoli, M. 2012. Development of a compact roll over protective structure for agricultural wheeled narrow track tractors. in Proc. SHWA, 3-6 September, Ragusa, Italy. pp 131-136.
INAIL (Istituto Nazionale per l'Assicurazione contro gli Infortuni sul Lavoro) - Dipartimento Tecnologie di Sicurezza. 2011. Linee guida adeguamento trattori agricoli 0 forestali con piano di carico (motoagricole).

INAIL (Istituto Nazionale per l'Assicurazione contro gli Infortuni sul Lavoro). 2012. Rapporto annuale 2012.

Jarén, C., Alfaro, J.R., Arazuri, S., De León, J.L.P., Arana, J.I. Assessing rollover safety provided by ROPS tests following SAE standard J1194 versus OECD code 4. Transactions of the ASABE. 2009. 52: 1453-9.

Kim, H.J., Choi, S., Kim, K.W., Kim, J.S., Kim, J.O., Kim, Y.Y., Kim, H.K., Kwon, S.H. A study on improving the tractor ROPS and seatbelt use of Korean farmers. American Society of Agricultural and Biological Engineers Annual International Meeting. 2011.

Laurendi, V., Vita, L. Documento tecnico redatto dal Gruppo di Lavoro Nazionale istituito presso INAIL. Adeguamento dei trattori agricoli 0 forestali. INAIL. 2011.

Mangado, J., Arana, J.I., Jarén, C., Arazuri, S., Arnal, P. Design calculations on roll-over protective structures for agricultural tractors. Biosystems Engineering. 2007. 96: 181-91.

Murphy, D.J., Myers, J., McKenzie Jr., E.A., Cavaletto, R., May, J., Sorensen, J. Tractors and rollover protection in the United States. Journal of Agromedicine. 2010. 5: 249-63.

Myers, J.R. Prevalence of roll-over protective structure (ROPS)equipped tractors on hispanic-operated farms in the United States. Journal of Agromedicine. 2010. 15: 137-47.

OECD Codes. OECD Standard Codes for the official testing of agricultural and forestry tractors. Available at, OECD Headquarters, Paris, France. 2009. http://www.oecd.org

Rondelli, V., Guzzomi, A.L., Selecting ROPS safety margins for wheeled agricultural tractors based on tractor mass. Biosystems Engineering. 2010. 105: 402-41.

Si, J., Wang, G., Yan, Z., Wang, J., Hao, W. Design and performance simulation of ROPS and energy-absorbing device. Nongye Jixie Xuebao/Transactions of the Chinese Society of Agricultural Machinery. 2010. 41: 20-4. 